科 学 通报

\title{
$\mathrm{PbTiO}_{3}$ 薄膜的热释电特性研究*
}

\author{
卢朝靖 邝安祥 王世敏 黄桂玉
}

(湖北大学物理系, 武汉 430062)

\section{关镇词 $\mathrm{PbTiO}_{3}$ 薄膜、介电、热释电性质、烧结温度、膜厚}

铁电 $\mathrm{PbTiO}_{3}$ 薄膜具有优良的热释电性质, 因其有介电常数 $\varepsilon_{\mathrm{r}}$ 小、热释电系数 $\gamma$ 大、居里温 度高、体积热容量小、 $\gamma$ 和 $\varepsilon_{\mathrm{r}}$ 的温度系数小等优点, 受到人们的极大关注. 国外已用溅射法制 备的 $\mathrm{PbTiO}_{3}$ 薄膜作成了热释电红外探测器 ${ }^{1 !}$. 我们用 sol-gel 方法在单晶 $\mathrm{Si}$ 衬底上制备了 $\mathrm{PbTiO}_{3}$ 薄膜, 并简要报道了它的电学性质 ${ }^{[2]}$. 本文着重研究 $\mathrm{PbTiO}_{3}$ 薄膜的热释电特性, 主要 介绍极化条件、烧结温度、膜厚等工艺因素对介电、热释电性质的影响, 以及热释电系数随温 度的变化关系, 优化了工艺过程。

\section{1 实 验 方 法}

$\mathrm{PbTiO}_{3}$ 薄膜的制备同文献[2]. 为测量薄膜的电学性质, $0.3-4.0 \mu \mathrm{m}$ 厚的薄膜沉积在 $\mathrm{P}$ 型 $\mathrm{Si}$ 单晶衬底 $(\rho \sim 0.005 \Omega \cdot \mathrm{cm})$ 上, 直接以衬底作下电极; 在薄膜上表面浌射一层厚约 $100 \mathrm{~nm}$ 的金薄膜作上电极, 电极尺寸 $\leftrightarrow 1 \mathrm{~mm}$.

薄膜的介电常数 $\varepsilon_{\mathrm{r}}$ 和介电损耗 $\tan \delta$ 用 $4192 \mathrm{~A}$ 型低频阻抗分析仪测量, 测量频率 $100 \mathrm{kHz}$. 介电常数由下式计算: $\varepsilon_{\mathrm{r}}=C d / S \varepsilon_{0}$, 其中 $C$ 为实测电容, $d$ 是膜厚, $S$ 是上电极面积, $\varepsilon_{0}=$ $8.85 \times 10^{-12} \mathrm{~F} / \mathrm{m}$.

采用 PH-1 型数字电荷仪和数字积分方法测量薄膜的热释电系数, 测量前试样在 $120 \mathrm{kV} / \mathrm{cm} 、 200^{\circ} \mathrm{C}$ 极化 $20 \mathrm{~min}$. 若薄膜从温度 $T$ 上升到 $T+\Delta T$ 释放的表面电荷是 $\Delta Q$, 则薄 膜在温度 $T$ 的热释电系数为 $\gamma=\Delta Q / S \cdot \Delta T$. 薄膜的热释电性能用 $F_{\mathrm{V}}=\gamma / C_{\mathrm{v}} \varepsilon_{\mathrm{r}}$ 和 $F_{\mathrm{m}}=\gamma / C_{\mathrm{v}} \sqrt{\varepsilon_{\mathrm{r}} \tan \delta}$ 评价, $F_{\mathrm{v}}$ 和 $F_{\mathrm{m}}$ 分别为对应电压响应度和比探测率的性能指数, $C_{\mathrm{v}}$ 是体积 比热容, 对 $\mathrm{PbTiO}_{3}$ 薄膜 $C_{\mathrm{v}}=3.2 \mathrm{~J} / \mathrm{cm}^{3} \cdot \mathrm{K}^{[3]}$.

\section{2 结 果 和 讨 论}

\section{1 极化条件的确定}

在 $\mathrm{Si}$ 单晶上生长的 $\mathrm{PbTiO}_{3}$ 陶瓷薄膜必须经极化处理后才能检测试样的热释电电荷. 实 验研究表明, 最佳极化条件是在 $120 \mathrm{kV} / \mathrm{cm} 、 200^{\circ} \mathrm{C}$ 极化 $20 \mathrm{~min}$. 显然, 适当提高温度, 有利于薄 膜中的电畴获得能量发生偏转, 增强极化效果. 图 1 示出了厚 $2.1 \mu \mathrm{m} 、 650^{\circ} \mathrm{C}$ 烧结的 $\mathrm{PbTiO}_{3}$ 薄

1993-06-16 收稿.

* 国家 “ 863 ”高技术计划资助项目. 


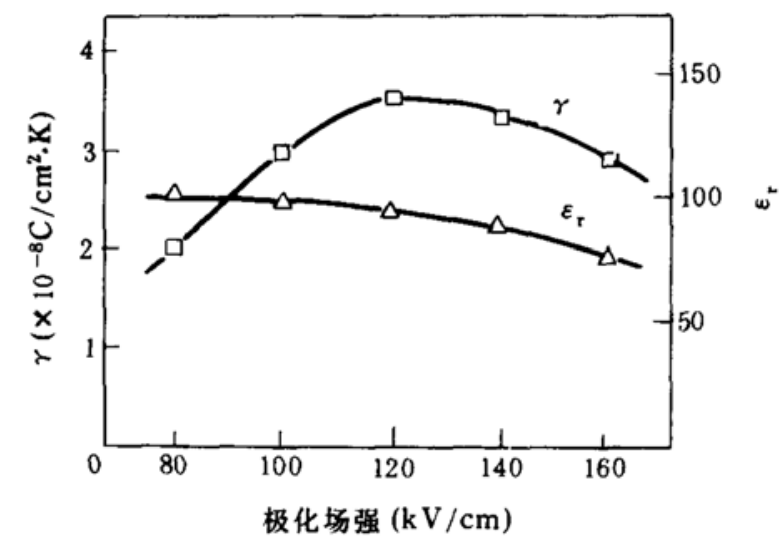

图 1 极化场强对热释电系数 $\gamma$ 和相对介电常数 $\varepsilon_{\mathrm{r}}$ 的影响

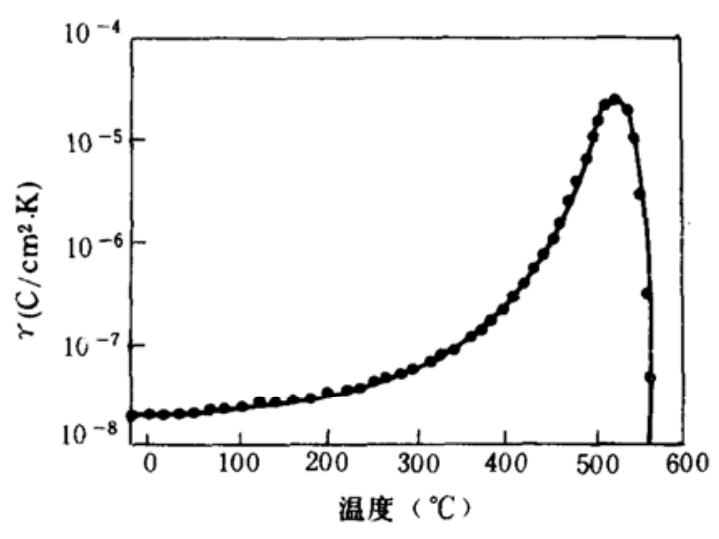

图 2 薄膜热释电系数随温度变化的关系曲线

膜的室温热释电系数 $\gamma$ 和相对介电常数 $\varepsilon_{\mathrm{r}}$ 随极化场强变化的曲线. $\varepsilon_{\mathrm{r}}$ 随极化场强的增大而 单调降低. $\gamma$ 在 $120 \mathrm{kV} / \mathrm{cm}$ 达到极大后, 继续增加极化场强, 热释电系数减小. 这可能是由于试 样中杂质、裂缝或气孔在高极化电场下导致薄膜内部部分击穿的缘故.

\section{2 热释电系数随温度的变化}

图 2 是厚 $2.1 \mu \mathrm{m} 、 650^{\circ} \mathrm{C}$ 烧结的 $\mathrm{PbTiO}_{3}$ 薄膜的 $\gamma-T$ 曲线. 可以看到, 在 $-10^{\circ} \mathrm{C}$ 至 $300^{\circ} \mathrm{C}$ 的升 温过程中, 由于晶格常数 $a$ 和 $c$ 变化引起自发极化改变不大, $\gamma$ 的温度系数较小. 薄膜的准居 里温度 $T_{\mathrm{c}}$ 约 $520^{\circ} \mathrm{C}$, 比 $\mathrm{PbTiO}_{3}$ 陶瓷的居里点 $490^{\circ} \mathrm{C}$ 高; 而且在居里温度附近薄膜的热释电系 数 - 温度曲线峰形不如 $\mathrm{PbTiO}_{3}$ 陶瓷的那样尖锐, 这是因为薄膜中受内应力作用的各晶粒的居 里温度相互不同, 而薄膜的 $\gamma$ 又是所有晶粒的 $\gamma$ 的平均值.

\section{3 烧结温度对介电性和热释电性的影响}

薄膜的介电性和热释电性强烈依赖于薄膜的晶体结构. 图 3 示出了薄膜的介电常数、介 电损耗、热释电系数、热释电性能指数 $F_{\mathrm{v}}$ 和 $F_{\mathrm{m}}$ 随烧结温度变化的关系曲线, 薄膜厚度 $2.1 \mu \mathrm{m}$. 随着烧结温度的提高, 薄膜的结晶质量改善, 晶粒尺寸增大, 介电常数增加. 但是, 薄膜的介 电常数比陶瓷的 $(\sim 200)$ 小, 这与薄膜中的晶粒细小有关. 薄膜的介电损耗在 $550^{\circ} \mathrm{C}$ 出现极 小值, 这对应于焦绿石相刚好在 $550^{\circ} \mathrm{C}$ 完全消失. 热释电系数在 $600^{\circ} \mathrm{C}$ 左右激剧增加, 在 $650^{\circ} \mathrm{C}$ 以上基本饱和在 $3.6 \times 10^{-8} \mathrm{C} / \mathrm{cm}^{2} \cdot \mathrm{K}$. 电压响应度品质因数 $F_{\mathrm{v}}$ 和比探测率品质因数 $F_{\mathrm{m}}$ 随烧 结温度变化的规律基本相同, 在 $650^{\circ} \mathrm{C}$ 出现极大值, 分别 是 $0.9 \times 10^{-10} \mathrm{C} \cdot \mathrm{cm} / \mathrm{J}$ 和 $7.2 \times 10^{-9} \mathrm{C} \cdot \mathrm{cm} / \mathrm{J}$.

\section{4 薄膜厚度对介电和热释电性质的影响}

薄膜的介电和热释电性质同时受薄膜厚度的影响. 图 4 是介电常数、介电损耗、热释电系 数、热释电性能指数 $F_{\mathrm{v}}$ 和 $F_{\mathrm{m}}$ 随膜厚变化的关系曲线, 薄膜烧结温度 $650^{\circ} \mathrm{C}$. 可以看到,在 $1 \mu \mathrm{m}$ 以下, 随着薄膜厚度的增加, 介电常数急增, 介电损耗陡降; 在 $1 \mu \mathrm{m}$ 以上, $\varepsilon_{\mathrm{r}}$ 基本稳定在 $120-130$ 之间, $\tan \delta$ 保持在 0.02 左右. 热释电系数在 $2 \mu \mathrm{m}$ 左右达到极大值 $3.6 \times 10^{-8} \mathrm{C} / \mathrm{cm}^{2} \cdot \mathrm{K}$. 膜厚对介电和热释电性质的影响主要与薄膜表面层和界面层的特殊性质 有关, 由于表面层和界面层的微观结构不同于薄膜体. 在样品较薄时, 表面层或界面层厚度 与薄膜厚度的比值较大, 影响也较大; 随着样品厚度的增加, 这种比值变小, 影响随之减弱. 


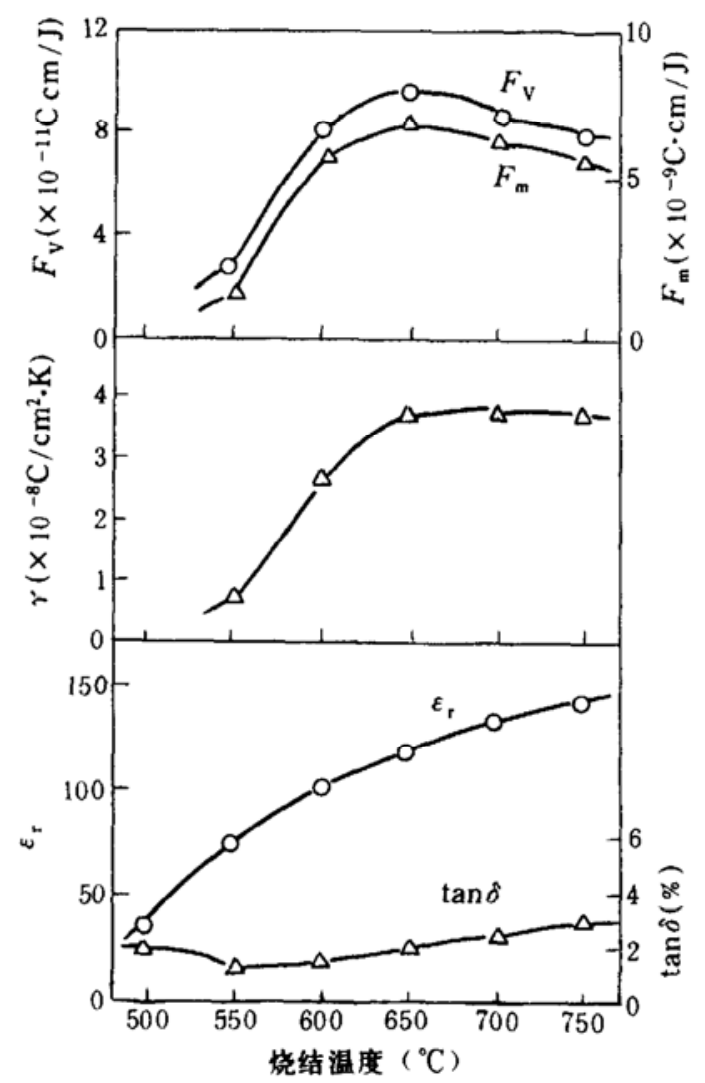

图 3 相对介电常数 $\varepsilon_{\mathrm{r}}$,介电损耗 $\tan \delta$, 热释电 系数 $\gamma$ 、热释电性能指数 $F_{\mathrm{v}}$ 和 $F_{\mathrm{m}}$ 随烧结温度变 化的曲线 (薄膜厚度 $2.1 \mu \mathrm{m}$ )

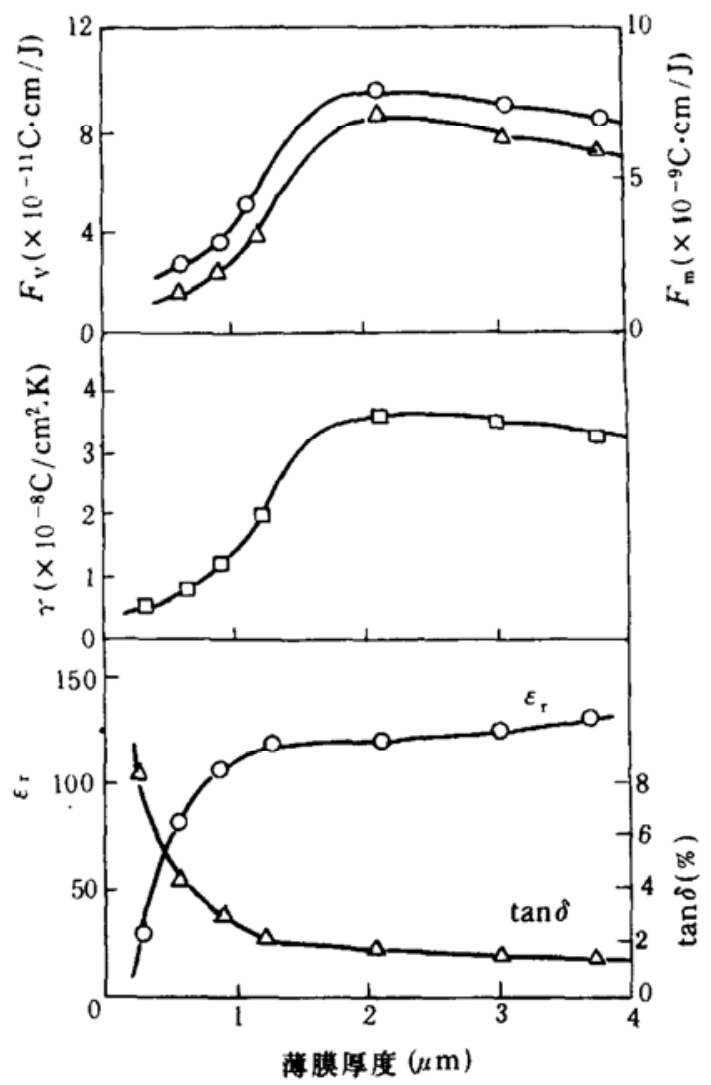

图 4 相对介电常数 $\varepsilon_{\mathrm{r}}$ 介介电损耗 $\tan \delta$ 热释 电系数 $\gamma$ 、热释电性能指数 $F_{\mathrm{v}}$ 和 $F_{\mathrm{m}}$ 随膜厚 变化的关系曲线 (烧结温度 $650^{\circ} \mathrm{C}$ )

另一方面, 即使在同一温度烧结, 较薄的薄膜中的晶粒尺寸较小.

\section{3 结 论}

用 sol-gel 法在单晶 $\mathrm{Si}$ 上生长的 $\mathrm{PbTiO}_{3}$ 薄膜是一种好的热释电红外探测器材料. 其热释 电性能指数可同用贼射法制备的 $\mathrm{PbTiO}_{3}$ 薄膜媲美 ${ }^{[4,5]}$, 是 $\mathrm{PbTiO}_{3}$ 陶瓷的 3 倍 ${ }^{[6]}, F_{\mathrm{v}}$ 和 $F_{\mathrm{m}}$ 分别达 $0.9 \times 10^{-10} \mathrm{C} \cdot \mathrm{cm} / \mathrm{J}$ 和 $7.2 \times 10^{-9} \mathrm{C} \cdot \mathrm{cm} / \mathrm{J}$. 最佳工艺参数是: 厚约 $2 \mu \mathrm{m}$ 的薄膜在 $650^{\circ} \mathrm{C}$ 烧 结, 在 $120 \mathrm{kV} / \mathrm{cm} 、 200^{\circ} \mathrm{C}$ 极化 $20 \mathrm{~min}$. 薄膜的准居里温度为 $520^{\circ} \mathrm{C}$.

\section{参 考 文 献}

[1] Okuyama, M., Hamakawa, Y., Ferroelectrics, 1985, 63:243-252.

[2]卢朝靖、王世敏、饫安样等,科学通报, 1993, 28(2): 110-- 112 .

[3] Beerman, H. P., Infrared Phys., 1975, 15: 225-231.

[4] Iijima, K., Takayama, R., Tomita, Y. et al., J. Appl. Phys., 1986, 60: 2914- 2920.

[5] lijima, K., Tomita, Y., Takayama, R. et al., J. Appl. Phys., 1986, 60(1):361-367.

[6] Adachi, H., Mitsuyu, T., Yamazaki, O. et al., Jpn. J. Appl. Phys. Suppl., 1985, 24:3-10. 